\title{
PENGGUNAAN METODE RESPONDENT DRIVEN SAMPLING (RDS) DALAM SURVEY PEMASARAN BERAS DI PROVINSI KEPULAUAN RIAU
}

\author{
Herena Pudjihastuti \\ Mathematics and Statistics Department, School of Computer Science, Binus University \\ Jln. K.H. Syahdan No. 9 Palmerah, Jakarta Barat 11480 \\ herena03@yahoo.com
}

\begin{abstract}
As a Free Trade Zone (FTZ), the province of Riau Islands has a different pattern of strategic commodity (such as rice) marketing comparing to other regions in Indonesia. To anticipate and control the negative effects of the implementation of FTZ policy, It is necessary to study about rice marketing trade system in the Riau Islands region. The study was conducted to identify patterns of supply and marketing of food (rice) and analyze the marketing margin and marketing efficiency as well as the factors that influence it. The study was conducted through desk study and field surveys. Secondary data was collected from various sources and primary data collected through interviews with selected respondents using Respondent Driven Sampling method (RDS). The study shows that the structure of the rice market in Riau Islands can be categorized as monopolistic. Most of the rice supply comes from outside the region and import, the supply chain is quite simple, the price is relatively stable and relatively efficient marketing and resilience of rice reserves are relatively high for merchants. Nevertheless, the Riau islands will be very susceptible to interference distribution. Required efforts of the provincial government of Riau Islands to provide sufficient rice reserves. This paper gives an example of the use of the RDS method in marketing surveys.
\end{abstract}

Keywords: marketing survey, snowball sampling, responden driven sampling

\begin{abstract}
ABSTRAK
Sebagai kawasan Free Trade Zone (FTZ), Provinsi Kepulauan Riau ,maka memiliki pola pemasaran komoditas strategis (seperti beras)yang berbeda dengan di wilayah Indonesia lainnya. Untuk mengantisipasi dan mengontrol efek negatif dari pelaksanaan kebijakan FTZ diperlukan pengetahuan tentang pola tata niaga di wilayah tersebut. Studi dilakukan untuk mengidentifikasi pola pasokan dan pemasaran pangan (beras) dan menganalisis marjin pemasaran dan efisiensi pemasaran serta faktor-faktor yang mempengaruhinya. Studi dilakukan melalui desk study dan survei lapangan. Data sekunder dikumpulkan dari berbagai sumber dan data primer dikumpulkan melalui wawancara terhadap responden yang dipilih menggunakan metode Responden Driven Sampling (RDS). Hasil studi menunjukkan bahwa struktur pasar beras di Kepulauan Riau dapat dikategorikan sebagai pasar persaingan monopolistik. Sebagian besar pasokan beras berasal dari luar daerah dan impor, rantai pasokannya tergolong cukup sederhana, harga relatif stabil dan pemasaran relatif efisien dan ketahanan cadangan beras bagi pedagang relatif tinggi. Walaupun demikian, kepulauan Riau akan sangat rentan terhadap gangguan distribusi. Diperlukan upaya dari pemerintah provinsi Kepulauan Riau untuk menyediakan cadangan beras yang cukup. Paper ini memberikan contoh penggunaan Metode RDS dalam survey pemasaran.
\end{abstract}

Kata kunci: survey marketing, snowball sampling, responden driven sampling 


\section{PENDAHULUAN}

Provinsi Kepulauan Riau merupakan salah satu provinsi yang terdiri dari banyak gugusan pulau besar dan kecil yang tersebar di seluruh wilayah provinsi. Provinsi Kepulauan Riau terdiri dari tujuh kabupaten/kota yang terletak di pulau-pulau terpisah. Sebagian besar penduduk berada di pulau berukuran relatif besar yaitu Batam yang merupakan Pusat Pengembangan Industri dan Perdagangan (56,2\%), Karimun yang menjadi pusat perekonomian hampir sebagian besar masyarakatnya $(12,7 \%)$, dan Tanjungpinang yang merupakan ibukota provinsi yang terletak di Pulau Bintan (11,2\%). Sebagian besar bahan pangan yang dibutuhkan masyarakat Kepulauan Riau, didatangkan dari luar provinsi atau luar negeri, karena produksi dari wilayahnya sendiri tidak mencukupi.

Wilayah Batam, Bintan, dan Karimun (BBK) terletak pada jalur perlintasan pelayaran Internasional yang melayari selat Malaka. Kawasan ini berhadapan langsung dengan negara tetangga Singapura dan Malaysia (Johor Selatan). Sedangkan dalam skala regional antar provinsi, berdekatan dengan Kota Pekanbaru dan dilewati jalur PELNI. Karena letaknya yang strategis, Batam, Bintan, Karimun ditetapkan sebagai Kawasan Perdagangan Bebas dan Pelabuhan Bebas (KPBPB) atau Free Trade Zone (FTZ). Tujuan penetapan BBK sebagai kawasan FTZ adalah agar kawasan BBK menjadi pintu gerbang arus investasi asing ke Indonesia dan menjadi kawasan yang kompetitif dan berdaya saing tinggi. Sebagai wilayah perdagangan bebas, maka pemasaran komoditas strategis, seperti beras, akan memiliki pola yang berbeda dengan di wilayah Indonesia lainnya. Efek negatif yang kemungkinan terjadi dari kebijakan FTZ adalah bocornya produk impor ke wilayah lain di Indonesia. Untuk mengantisipasi dan mengontrol pelaksanaan kebijakan FTZ tersebut maka diperlukan pengetahuan tentang pola tata niaga di wilayah tersebut.

Survei pemasaran dilakukan antara lain dengan tujuan untuk menjelaskan bagaimana bentuk sinergi dari kegiatan-kegiatan ekonomi yang sudah berkembang atau yang berpotensi untuk dikembangkan. Informasi tentang pemasaran tersebut dapat digunakan untuk merancang berbagai intervensi untuk meningkatkan kinerja pasar, untuk mengidentifikasi kendala-kendala pasar seperti akses pada informasi, kelembagaan, dan regulasi perdagangan. Salah satu pendekatan dalam survei pemasaran adalah pendekatan kelembagaan yang bertujuan untuk menjawab pertanyaan tentang siapa yang paling berperan dalam proses tata niaga, siapa yang menentukan harga produk, siapa yang mendapat margin terbesar dan terkecil, apakah rantai tata niaga sudah efisien atau terlalu panjang dan apakah terjadi integrasi antar pasar. Dengan demikian objek yang diteliti adalah berbagai lembaga dan struktur kelembagaan yang terlibat dalam suatu rantai bisnis seperti produsen, broker/makelar, agen, pedagang besar/distributor/importir, pedagang pengumpul/tengkulak, pengolah, pedagang pengecer, dsb. Lembaga-lembaga pemasaran inilah aktor pengambil keputusan sesungguhnya dalam sistem tata niaga. Lembaga-lembaga pemasaran tersebut dapat dikatakan sebagai populasi yang tersembunyi (hidden population) karena kerangka samplingnya tidak tersedia dan akses untuk memperoleh informasi dari lembaga-lembaga tersebut sangat sulit.

Survei pemasaran seringkali menghadapi kendala dalam hal pengambilan sampel, karena sifat populasi yang akan diteliti seringkali sulit diakses baik karena kondisi geografis atau karena ketidakterbukaan dari pelaku pemasaran sehingga sulit ditembus oleh surveyor. Salah satu metode sampling yang sering digunakan untuk melakukan survei pemasaran adalah Snowball Sampling. Snowball sampling adalah suatu teknik penarikan contoh non-probabilitas yang sebagai alat untuk mempelajari struktur dari jaringan sosial. Snowball sampling digunakan di mana hanya ada sedikit pengetahuan tentang populasi sasaran. Metode Snowball Sampling mempunyai beberapa kelemahan antara lain tidak memenuhi asumsi keterwakilan sampel melalui pengacakan. Untuk mengatasi keterbatasan metode Snowball Sampling tersebut telah dikembangkan metode Responden-Driven Sampling (RDS). RDS ini mengkombinasikan metode Snowball Sampling dengan melakukan pengacakan agar memenuhi standar metode statistik probability sampling. Hal ini memungkinkan untuk menarik sampel statistik yang valid dari kelompok yang sebelumnya tidak terjangkau. 
Studi dilakukan untuk: (1) Mengidentifikasi dan mempelajari pola pasokan dan pemasaran pangan (beras) beserta permasalahannya. (2) Menganalisis marjin pemasaran dan efisiensi pemasaran serta faktor-faktor yang mempengaruhinya. Manfaat studi diharapkan akan memberikan pemahaman tentang pola dan kinerja pemasaran beras di Provinsi Kepulauan Riau, termasuk informasi tentang dampak penerapan kebijakan FTZ. Paper ini akan memberikan ringkasan hasil studi tersebut dan diharapkan menjadi contoh penggunaan teknik sampling RDS untuk survei pemasaran produk pangan.

\section{Kajian Teoritik Metode RDS}

Menurut Anatan. L dan Ellitan. L (2009), rantai pasokan adalah suatu sistem tempat organisasi menyalurkan barang produksi dan jasa kepada para pelanggan. Rantai ini merupakan jaring yang menghubungkan berbagai organisasi yang saling berhubungan dan mempunyai tujuan yang sama yaitu mengadakan pengadaan barang (procurement) atau menyalurkan (distribution) barang secara efisien dan efektif sehingga akan tercipta nilai tambah bagi produk tersebut. Rantai pasokan merupakan logistic network yang menghubungkan suatu mata rantai antara lain suppliers, manufacturer, distribution, retail outlets, dan customers.

Snowball sampling adalah teknik penarikan contoh non-probabilitas yang cocok digunakan untuk melakukan penelitian di mana anggota populasi sulit dicari atau diakses (hidden population) dan sampling frame tidak tersedia. Snowball Sampling menggunakan sekelompok kecil informan awal, yang kemudian melalui jaringan sosialnya, mereka mencalonkan responden lain yang berpotensi memberikan kontribusi informasi yang dibutuhkan peneliti. Istilah Snowball Sampling mencerminkan analogi bola salju yang menggelinding membentuk bola yang semakin membesar ukurannya (Salganik and Heckathorn, 2004).

Beberapa jenis metode Snowball Sampling adalah: (1) Metode Linear; meminta dari sampel pertama dari responden awal, untuk menunjuk satu responden berikutnya dan dari sampel ke dua juga diminta untuk menunjuk satu sampel selanjutnya, dan seterusnya. (2) Non discriminative exponential method; pewawancara meminta responden awal untuk menunjukkan semua yang mereka kenal dalam populasi sasaran, dan peneliti mewawancara semua individu yang ditunjuk tersebut. Cara yang sama diterapkan pada siklus berikutnya. (3) Discriminative exponential method; sama dengan metode non discriminative, perbedaannya adalah peneliti memilih secara acak beberapa individu yang ditunjuk responden sebelumnya (Voicu, M.C., 2009).

Prosedur pengambilan sampel dengan metode Snowball Sampling adalah sebagai berikut: (1) Rencanakan daftar indikasi responden yang mungkin akan berpartisipasi (dapat berubah jika diperlukan). (2) Lakukan pendekatan terhadap calon responden dan mencari tahu nomor untuk menghubungi. (3) Lakukan kontak terhadap responden dan minta dia untuk menunjuk responden lain yang relevan. (4) Lanjutkan snowballing dengan kontak berikutnya untuk mendapatkan responden selanjutnya. (5) Pastikan keragaman kontak dengan memperluas profil dari orang yang terlibat dalam snowballing.

Keberhasilan teknik ini sangat tergantung pada kontak awal dan koneksi dibuat. Perlu dibuat pre-asumsi bahwa responden tersebut mengenal orang lain yang relevan. Penting untuk berhubungan dengan orang-orang yang populer dan terhormat untuk menciptakan lebih banyak kesempatan untuk berkembang dan dapat diandalkan. Teknik Snowball Sampling mempunyai kelebihan dalam mengidentifikasi populasi tersembunyi dan mendapatkan responden anggota populasi tersembunyi. Walaupun demikian metode tersebut mempunyai beberapa kelemahan yaitu: (1) Bias; keberhasilan metode sangat ditentukan pemilihan awal dan sangat bergantung pada kemampuan untuk menunjuk sampel yang tepat. (2) Tidak Acak; Snowball Sampling bertentangan dengan asumsi yang mendukung gagasan konvensional seleksi acak dan keterwakilan sampel. (3) Ukuran sampel yang tidak jelas; tidak ada cara untuk mengetahui ukuran total keseluruhan populasi. (4) Kelemahan lain dari Snowball Sampling adalah ketidakpastian apakah sampel yang dipilih sudah tepat atau tidak. 
Untuk meningkatkan efisiensi dari metode Snowball Sampling, Snijders ( 1992) telah menciptakan suatu metode one-cycle referral untuk mengestimasi populasi tersembunyi dengan cara memilih suatu kelompok awal yang heterogen, dan setiap anggota dalam kelompok diminta menyusun daftar semua orang dalam populasi target yang dikenalnya. Metode lain yang juga diusulkan untuk memperbaiki kelemahan metode Snowball Sampling adalah metode Respondent Driven Sampling (RDS) yang mengkombinasikan penunjukan responden (chain referral) dan suatu metode matematis untuk mengkompensasi pemilihan sampel yang dilakukan secara tidak acak.

Metode dasar yang digunakan untuk memilih RDS adalah sebagai berikut: Awalnya, sejumlah individu dari populasi yang diketahui peneliti, dipilih secara acak dalam seed. Setiap seed, diminta untuk menunjuk orang lain yang mereka kenal dalam populasi. Ketika seseorang telah dipilih, mereka diminta untuk memberikan informasi yang sesuai dengan penelitian. Untuk mendorong respon, dapat diberikan hadiah (kupon) kepada responden. Proses yang sama dilakukan pada siklus berikutnya.

Perbedaan RDS dengan metode tradisional snowballing adalah sebagai berikut. Pertama, metode Snowball Sampling menggunakan insentif hanya untuk mengkompensasi partisipasi responden, sementara RDS menggunakan sistem dual stimulan yaitu hadiah diberikan karena responden telah diwawancarai (reward primer), selain itu juga ditambah hadiah untuk jasanya merekrut anggota lain dari populasi tersembunyi (reward sekunder). Dengan hadiah sekunder tersebut, perekrut diberi tambahan tekanan, yang diharapkan dapat mengurangi non-respon error karena adanya efek hadiah dan pertemanan. Kedua, subyek bukan diminta untuk mengidentifikasi dan memberi nama anggota lain yang dikenal, tetapi diminta untuk merekrut sendiri teman-temannya, sehingga mengurangi kecenderungan responden untuk menyembunyikan orang yang ditunjuk tetapi menawarkan responden kesempatan untuk memutuskan sendiri apakah mereka bersedia untuk berpartisipasi dalam survei. Ketiga, jumlah responden yang dapat direkrut dibatasi oleh jumlah kupon yang tersedia (biasanya 3 atau 4), sehingga meminimalkan pengaruh responden awal pada struktur sampel akhir. Pembatasan jumlah orang yang direkrut tersebut merangsang pencapaian rantai rekrutmen yang panjang sehingga meningkatkan kesempatan untuk dapat mendekati daerah yang paling tersembunyi dari populasi target. Dan terakhir, hubungan antara perekrut dan orang-orang yang direkrut didokumentasikan sehingga memungkinkan penilaian dan penyesuaian kesalahan perekrutan pada tahap analisis data.

Lain halnya dengan sampling traditional yang membuat pendugaan populasi secara langsung dari sampel (Gambar 1), RDS menggunakan metode tidak langsung. Pertama, sampel digunakan untuk menduga tentang social network yang menghubungkan populasi. Kemudian informasi tentang social network tersebut digunakan untuk menduga proporsi populasi pada kelompok-kelompok yang berbeda (Gambar 2). Dengan menduga secara tidak langsung dari sampel ke populasi, maka permasalahan yang seringkali terjadi pada sampel chain referral akan dapat dihindari.

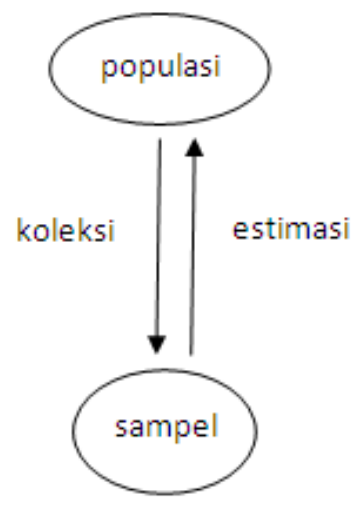

Gambar 1 Estimasi pada tradisional 


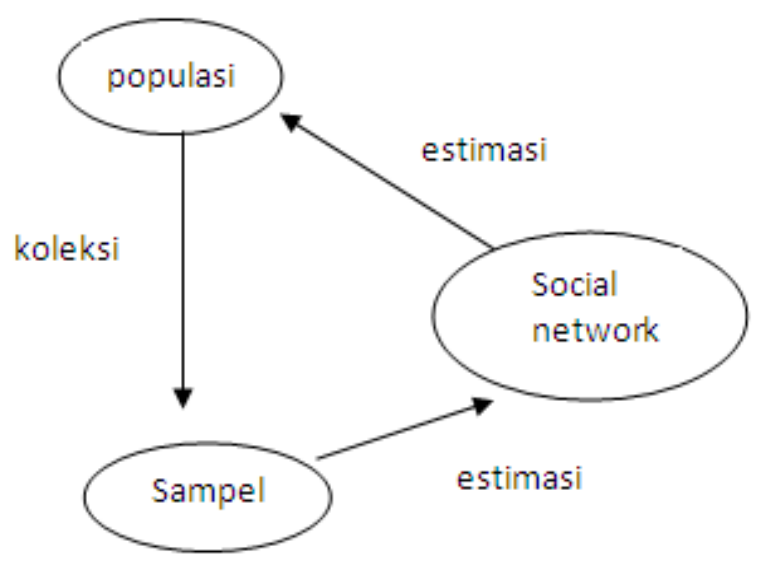

Gambar 2 Estimasi pada metode RDS sampling

\section{METODE}

\section{Desain Penelitian}

Studi dilakukan melalui: (1) Desk study untuk mengidentifikasi dan mempelajari sistem distribusi beras di kepulauan Riau dari sumber data sekunder dan berbagai referensi serta hasil-hasil kajian yang telah dilakukan oleh pihak-pihak lain. (2) Melaksanakan survei lapangan untuk memperoleh gambaran tentang arus distribusi (asal pembelian dan tujuan penjualan gabah/beras) di setiap tingkat pelaku pemasaran komoditas tersebut di Provinsi Kepulauan Riau.

Data sekunder dikumpulkan dari berbagai sumber seperti BPS Provinsi dan Kabupaten, Dinas Pertanian Provinsi dan Kabupaten, Badan Ketahanan Pangan Provinsi, Dinas Perdagangan Provinsi, Divre (Dolog), dan sebagainya. Data primer dikumpulkan melalui wawancara dan pengisian kuesioner dari responden yang dipilih, yaitu: Petani dan Penggilingan padi di Kabupaten, Pedagang Pengumpul, Pedagang grosir di Pasar Induk atau Pasar terbesar di Provinsi Kepulauan Riau, dan Pedagang eceran di Pasar di Kabupaten/Kota.

\section{Metode Sampling}

Pemilihan sampel dilakukan menggunakan metode Responden Driven Sampling (RDS) dengan memodifikasi snowball sampling jenis discriminative exponential dengan memilih seed secara acak di awal pemilihan sampel. Sampel untuk survei dipilih dari tiga kabupaten/kota di provinsi Kepulauan Riau yaitu Batam, Karimun dan Tanjung Pinang yang merupakan wilayah FTZ. Dari setiap kabupaten dipilih tiga distributor terbesar secara acak dari daftar distributor yang tersedia. Setiap distributor terpilih tersebut diminta untuk menunjuk dan mewawancari tiga lembaga pemasaran tempat membeli produk dan tiga lembaga pemasaran tempat menjual produk. Cara yang sama dilakukan pada siklus berikutnya (Gambar 3). Jumlah siklus tergantung dari panjang rantai pemasaran. Setiap lembaga pemasaran diberikan insentif untuk jasanya mau diwawancarai dan merekrut lembaga pemasaran lainnya. 


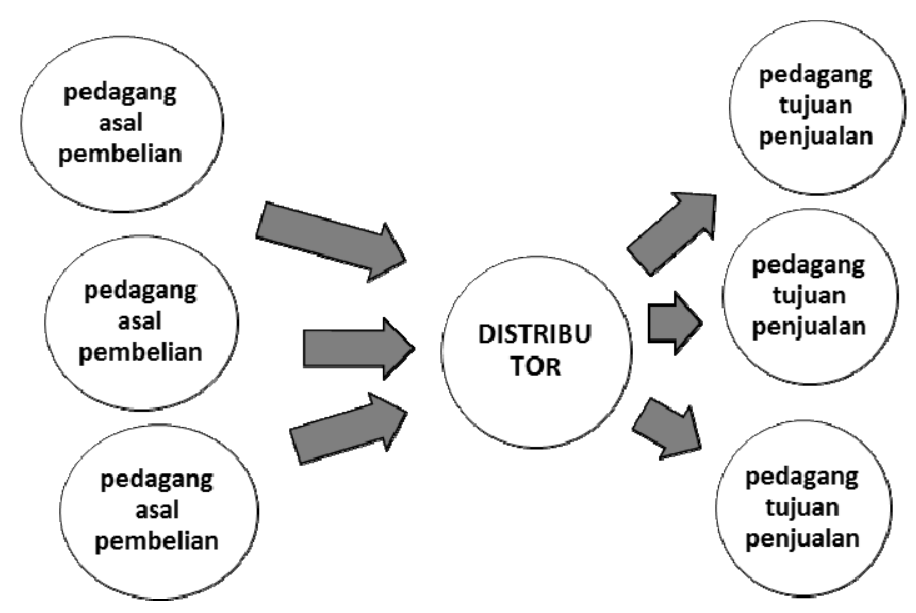

Gambar 3 Satu siklus pemilihan sampel

\section{Metode Analisis}

Analisis yang dilakukan meliputi pertama, Analisis Struktur Pasar (Market Structure) yaitu identifikasi rantai pasar yang strategis dan yg diperkirakan rentan mengalami gejolak pasar. Kedua, Analisis Perilaku Pasar (Market Conduct) yaitu (a) Identifikasi perilaku pasar terutama jika terjadi gejolak pasar yang dilihat dari aspek. (b) Perubahan pembentukan harga. (c) Tingkat persaingan. (d) Perubahan dalam penjualan. (e) Perubahan berat/persatuan atau ukuran persatuan. (d) Perubahan standar/kualitas. Ketiga, Analisis Kinerja Pasar (Market Performance) yaitu (a) Identifikasi kinerja pasar yang dilihat dari aspek. (b) Stabilitas harga pangan menurut waktu. (c) Perbedaan harga menurut lokasi. (d) Biaya dan margin pemasaran. (e) Kewajaran keuntungan bagi pelaku pasar. (f) Kontinuitas pasokan dan distribusi pangan antar pasar. (g) Perubahan kualitas produk. Keempat, Margin Pemasaran adalah perbedaan antara harga eceran dengan harga di tingkat petani, namun demikian margin pemasaran dapat diukur pada masing-masing tingkat pada saluran pemasaran.

$$
\mathbf{M M}=\mathbf{C P}-\mathbf{P P}
$$

\section{Keterangan :}

$\mathrm{MM}=$ Marjin pemasaran (marketing margin).

$\mathrm{CP}=$ Harga produk pada tingkat konsumen (consumer price).

$\mathrm{PP}=$ Harga produk pada tingkat produsen (produser price)

Kelima, Efisiensi Pemasaran merupakan perbandingan antara output pemasaran dengan input pemasaran. Output bisa berupa kepuasan konsumen, sedangkan input merupakan masukan yang digunakandalam proses pemasaran. Efisiensi ini bisa berupa fisik maupun finansial.

$$
M E=(M M: V P) \times 100 \%
$$

Keterangan :

$\mathrm{ME}=$ Efisiensi pemasaran (marketing efficiency)

$\mathrm{MM}=$ Marjin pemasaran produk (marketing margin)

$\mathrm{VP}=$ Nilai produk yang di pasarkan (value of product) 
Keenam, Integrasi Pasar Vertikal dilakukan untuk menganalisis keterkaitan harga suatu pasar dengan harga pasar di bawahnya. Untuk menganalisis integrasi pasar ini digunakan regresi linear sederhana.

$$
\operatorname{Ln} P_{i}=\alpha+\beta \operatorname{Ln} P_{j}
$$

$\mathrm{P}_{\mathrm{i}}=$ harga di pasar kabupaten $\mathrm{i}$

$\mathrm{P}_{\mathrm{j}}=$ harga di pasar kabupaten $\mathrm{j}$

Jika Ho : $\beta=1$ diterima, maka harga di kabupaten i dan $\mathrm{j}$ terintegrasi

(Instrumen pengumpulan data ditribusi beras dan ayam pedaging terlampir)

\section{HASIL DAN PEMBAHASAN}

Hasil penelitian menunjukkan bahwa struktur pasar beras di Kepulauan Riau dikategorikan sebagai pasar persaingan monopolistik karena jumlah pembeli dan penjual di pasar beras di Provinsi Kepulauan Riau termasuk banyak, dan dilihat dari aspek heterogenitas produk yang diperdagangkan pun cukup bervariasi, serta kondisi hambatan untuk keluar masuk produk cukup tinggi. Selain itu, Rantai Pasokan komoditas beras di Kota Tanjung Pinang, Kota Batam, dan Kabupaten Karimun tergolong cukup sederhana karena hanya melibatkan pedagang besar (distributor), pedagang pengecer, dan konsumen.

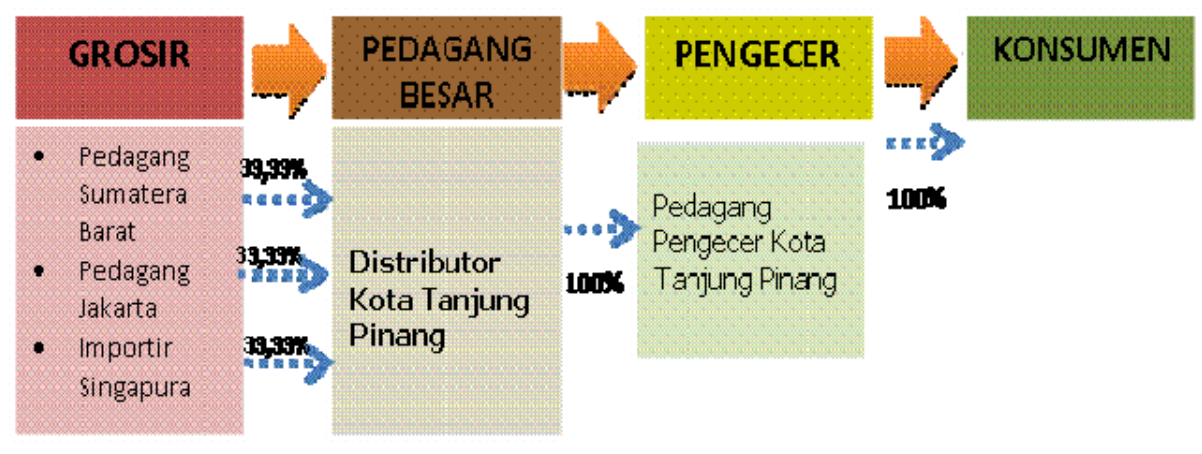

Gambar 4 Rantai Pasokan Beras di Kota Tanjung Pinang

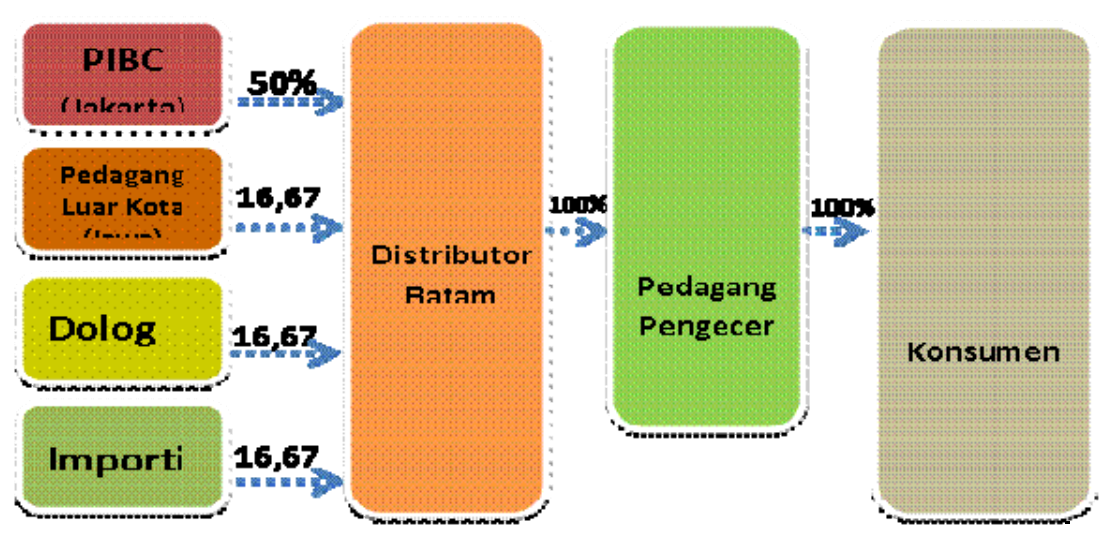

Gambar 5 Rantai Pasokan Beras di Kota Batam 


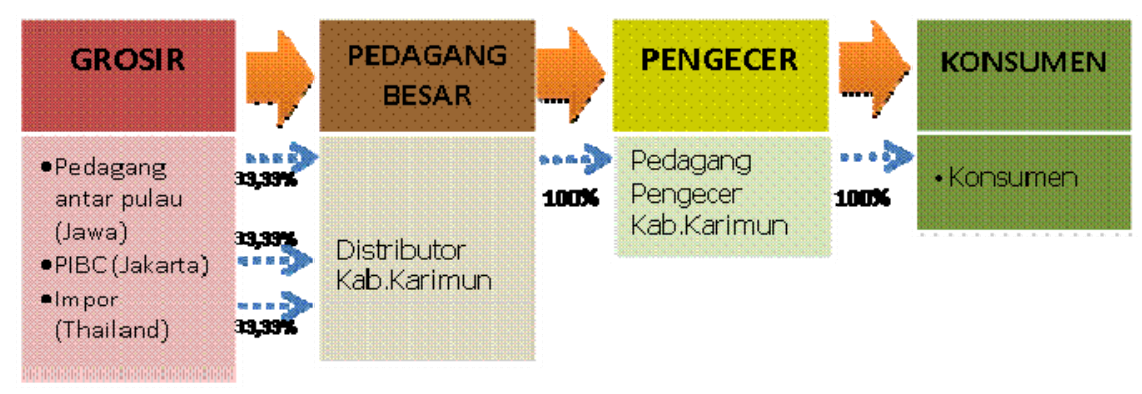

Gambar 6 Rantai Pasokan Beras di Kabupaten Karimun

Distribusi komoditas beras di Kota Tanjung Pinang, Kota Batam, dan Kabupaten Karimun seluruhnya didatangkan dari luar daerah. Komoditas beras diantaranya didatangkan dari PIBC (Jakarta), daerah Jawa lainnya selain Jakarta, Sumatera Barat, dan impor (Vietnam, Thailand, India dan Singapura). Hal tersebut menjadikan ketiga wilayah tersebut adalah wilayah konsumen dan ketersediaan beras di wilayah tersebut sangat tergantung pada wilayah lainnya.

Ketahanan cadangan beras bagi pedagang di Kota Batam relatif lebih tinggi jika dibandingkan dengan pedagang beras di Tanjung Pinang. Pedagang besar beras di Batam mempunyai ketahan cadangan beras pada kisaran 0,5 (dua minggu) s.d. satu bulan. Adapun pedagang besar beras di Tanjung Pinang mempunyai ketahanan cadangan beras antara 0,25 bulan (satu minggu) s.d. 0,5 bulan (dua minggu). Sementara itu ketahanan cadangan beras di Karimun cukup ekstrim. Di satu sisi ada pedagang yang menyatakan tidak mempunyai cadangan beras, tetapi di sisi lain, ada pedagang yang mempunyai daya tahan cadangan sampai dengan tiga bulan.

Pedagang pengecer beras di Batam mengelola cadangan beras antara 15 s.d. 30 kuintal beras. Adapun pedagang pengecer beras di Tanjung Pinang mengelola cadangan sebesar 5 s.d. 10 kuintal. Sedangkan pedagang pengecer di Karimun tidak menyebutkan bahwa mereka mengelola cadangan beras. Tetapi, Kesanggupan untuk menanggung risiko pasokan bagi pedagang pengecer di Tanjung Pinang lebih rendah bila dibandingkan dengan pedagang pengecer di Batam. Sementara, kekurangan pasokan beras di Batam sering terjadi di bulan Desember dan Januari, sedangkan di Tanjung Pinang dan Karimun kelangkaan pasokan beras sering terjadi pada bulan puasa.

Penyebab utama gejolak pasokan di Tanjung Pinang adalah adanya gangguan arus distribusi beras dari daerah pemasok akibat terjadinya gelombang tinggi/cuaca buruk, paceklik di sentra produsen beras, atau adanya kenaikan harga BBM. Sehingga, konsumen di Batam sebagian besar (88,89 persen) menyatakan bahwa mereka sering menghadapi kenaikan harga beras. Sebaliknya, konsumen di Karimun seluruhnya (100 persen) menyatakan mereka tidak mengalami gejolak harga beras, serta sebagian besar konsumen (66,67 persen) di Tanjung Pinang menyatakan tidak mengalami gejolak harga beras.

Harga beras di Batam relatif lebih stabil dibandingkan Tanjung Pinang dan Karimun, karena cadangan beras di Batam relatif lebih tinggi dan sarana prasarana transportasinya yang lebih baik. Oleh karena itu, perubahan harga beras di Batam sangat mempengaruhi harga beras di Tanjung Pinang demikian juga harga beras di Karimun juga cukup besar mempengaruhi harga beras di Tanjung Pinang. Sementara, pemasaran beras di Batam cenderung lebih efisien dibandingkan di Tanjung Pinang dan Karimun. 
Tabel 1 Efisiensi Pemasaran Beras di kabupaten Tanjung Pinang, Batam dan Karimun

\begin{tabular}{llc}
\hline \multicolumn{1}{c}{ Kabupaten } & \multicolumn{1}{c}{ Lembaga Pemasaran } & Efisiensi Pemasaran \% \\
\hline \multirow{2}{*}{ Batam } & Distributor & 3,35 \\
\multirow{2}{*}{ Tanjung Pinang } & Pedagang eceran & 1,86 \\
\multirow{2}{*}{ Karimun } & Distributor & 14,31 \\
& Pedagang eceran & 14,37 \\
& Distributor & 14,63 \\
& Pedagang eceran & 6,67 \\
\hline
\end{tabular}

Margin pemasaran beras yang diperoleh distributor umumnya lebih tinggi dibandingkan yang diperoleh pengecer. Margin pemasaran paling tinggi diperoleh oleh distributor dan pedagang eceran di Tanjung Pinang dan yang terendah di Batam

Tabel 2 Margin Pemasaran Beras

di Tanjung Pinang, Batam dan Karimun

\begin{tabular}{|c|c|c|c|c|c|}
\hline \multirow{2}{*}{ Kabupaten } & \multirow{2}{*}{$\begin{array}{l}\text { Lembaga } \\
\text { Pemasaran }\end{array}$} & \multirow{2}{*}{$\begin{array}{c}\text { Rata2 Harga beli } \\
(\mathrm{Rp} / \mathrm{kg}) \\
\end{array}$} & \multirow{2}{*}{$\begin{array}{c}\text { Rata2 Harga Jual } \\
(\mathrm{Rp} / \mathrm{kg}) \\
\end{array}$} & \multicolumn{2}{|c|}{ Margin Pemasaran } \\
\hline & & & & (Rp/kg) & $\%$ \\
\hline \multirow{2}{*}{ Batam } & Distributor & 8.317 & 8.567 & 250 & 3,58 \\
\hline & Pedagang eceran & 8.933 & 9.100 & 167 & 1,90 \\
\hline \multirow{2}{*}{ Tanjung Pinang } & Distributor & 7.450 & 8.650 & 1.200 & 16,79 \\
\hline & Pedagang eceran & 7.250 & 8.500 & 1.250 & 16,87 \\
\hline \multirow{2}{*}{ Karimun } & Distributor & 8.750 & 10.250 & 1.500 & 16,07 \\
\hline & Pedagang eceran & 9.333 & 10.000 & 667 & 7,02 \\
\hline
\end{tabular}

Analisis Keterpaduan Pasar menyimpulkan bahwa: (a) pasar beras di kabupaten Batam terintegrasi dengan pasar di kabupaten Tanjung Pinang (dan sebaliknya), tetapi tidak dengan kabupaten Karimun, (b). pasar beras di kabupaten Karimun terintegrasi dengan pasar di tanjung Pinang (dan sebaliknya), tetapi tidak terintegrasi dengan pasar di Batam. Bentuk integrasinya adalah sebagai berikut :

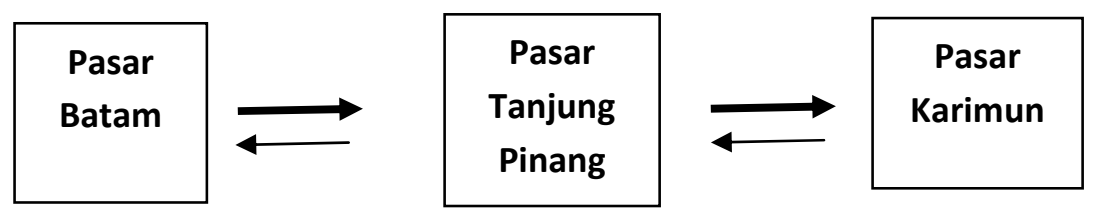

Gambar 7 Integrasi Pasar Beras

Kenaikan harga beras eceran di Kabupaten Batam sebesar 1\% akan menyebabkan kenaikan harga beras di Tanjung Pinang sebesar 11,39\%, dan sebaliknya kenaikan harga di Tanjung Pinang akan menyebabkan kenaikan harga di Batam sebesar 0,045\%. Demikian juga kenaikan harga beras eceran di Tanjung Pinang sebesar 1\% akan menyebabkan kenaikan harga beras di kabupaten Karimun sebesar $0,12 \%$, dan sebaliknya kenaikan harga di Karimun sebesar 1\% akan menyebabkan kenaikan harga di Tanjung Pinang sebesar 2,48 \%. Dengan demikian dapat disimpulkan bahwa harga beras di Batam sangat besar pengaruhnya terhadap harga beras di Tanjung Pinang, dan harga beras di Tanjung Pinang sangat mempengaruhi harga beras kabupaten Karimun. 
Tabel 3 Hubungan Harga Eceran Beras Antar Kabupaten

\begin{tabular}{llcccc}
\hline \multicolumn{1}{c}{$\begin{array}{c}\text { Dependent Variabel } \\
(\mathbf{L n})\end{array}$} & \multicolumn{1}{c}{$\begin{array}{c}\text { Independent Variabel } \\
(\mathbf{L n})\end{array}$} & $\boldsymbol{\beta}_{\mathbf{0}}$ & Sig level & $\boldsymbol{\beta}_{\mathbf{1}}$ & Sig level \\
\hline Harga Karimun & Harga Batam & 3,838 & 0,709 & 0,58 & 0,609 \\
Harga Batam & Harga Karimun & 8,66 & 0,00 & 0,047 & 0,609 \\
Harga Karimun & Harga Tj. Pinang & 7,897 & 0,00 & 0,122 & 0,064 \\
Harga Tj. Pinang & Harga Karimun & $-13,407$ & 0,244 & 2,48 & 0,064 \\
Harga Tj. Pinang & Harga Batam & $-94,298$ & 0,014 & 11,389 & 0,009 \\
Harga Batam & Harga Tj. Pinang & 8,67 & 0,00 & 0,045 & 0,009 \\
\hline
\end{tabular}

\section{SIMPULAN}

Berbeda dengan wilayah lain di Indonesia di mana struktur pemasaran beras umumnya berbentuk oligopoli, struktur pemasaran komoditas beras di Kepulauan Riau yang merupakan kawasan FTZ, dapat dikategorikan sebagai pasar persaingan monopolistik. Hal ini karena, suplai beras di Kepulauan Riau tergantung dari dari luar daerah (Jakarta, daerah Jawa lainnya, Sumatera Barat), dan impor (Vietnam, Thailand, India dan Singapura). Ketahanan cadangan beras bagi pedagang relatif tinggi dan harga relatif lebih stabil karena suplai dapat diperoleh dari berbagai wilayah. Walaupun demikian, dari sisi kemandirian pangan, kepulauan Riau akan sangat rentan terhadap gangguan distribusi baik dalam hal transportasi, kebijakan, harga, maupun ketersediaan di wilayah penyuplai. Oleh karena itu diperlukan upaya dari pemerintah provinsi Kepulauan Riau untuk menyediakan cadangan beras yang cukup. Sehingga, metode RDS diharapkan memberikan sampel yang lebih mewakili dibandingkan metode snowball sampling. Pembuktian bahwa estimasi menggunakan metode RDS lebih akurat dibandingkan metode snowball masih perlu dilakukan.

\section{DAFTAR PUSTAKA}

Anatan, L., Ellitan, L. (2009). Supply Chain Management, Teori dan Aplikasi. Jakarta: Alfabeta.

Badan Pusat Statistik. Kepulauan Riau Dalam Angka. 2013. Badan Pusat Statistik Kepulauan Riau. Kepulauan Riau Dalam Angka. 2013.

Snijders, T. A. B. (1992). Estimation on the basis of snowball samples: how to weight? Department of Statistics and Measurement Theory, University of Gronigen.

Salganik, M. J., Heckathorn, D. D. (2004). Sampling and Estimation in Hidden Populations Using Respondent-Driven Sampling. Sociological Methodology, 34(1), 193-240.

Voicu, M.C., Babonea, A.M (2011). Using The Snowball Method In Marketing Research On Hidden Populations. CKS - Challenges of the Knowledge, 2011(1), 1341.

Volz, Erik and Douglas D. Heckathorn. 2008. Probability Based Estimation Theory for RespondentDriven Sampling. Journal of Official Statistics, 24(1), 79-97. 